\title{
SKALA POSTRZEGANIA AGRESJI WOBEC PERSONELU (POAS) - DONIESIENIE WSTĘPNE
}

\author{
PERCEPTION OF AGGRESSION SCALE (POAS) - PRELIMINARY STUDY \\ Jakub Lickiewicz ${ }^{1}$, Kinga Sałapa ${ }^{2}$, Zofia Musiał $^{3}$, Mirosława Dzikowska ${ }^{3}$ \\ ${ }^{1}$ Zakład Psychologii Zdrowia, Instytut Pielęgniarstwa i Położnictwa \\ Wydział Nauk o Zdrowiu, Uniwersytet Jagielloński - Collegium Medicum \\ ${ }^{2}$ Zakład Bioinformatyki i Telemedycyny, Wydział Lekarski \\ Uniwersytet Jagielloński - Collegium Medicum \\ ${ }^{3}$ Zakład Pielęgniarstwa Klinicznego, Instytut Pielęgniarstwa i Położnictwa \\ Wydział Nauk o Zdrowiu, Uniwersytet Jagielloński - Collegium Medicum
}

DOI: https://doi.org/10.20883/pielpol.2018.10

\section{STRESZCZENIE}

Wstęp. Agresja pacjentów to problem w pracy pielęgniarek. Badania wskazują na jej duży wpływ na jakość opieki. Istnieje konieczność badania tego zjawiska w pracy personelu medycznego, brak jednak adekwatnych narzędzi.

Cel. Celem pracy było określenie psychometrycznych właściwości polskiej wersji 12-pytaniowego kwestionariusza postrzegania agresji POAS.

Materiał i metody. Wykonano tłumaczenie i tłumaczenie wsteczne oraz analizę czynnikową. W badaniu wzięło udział 150 studentek pielęgniarstwa po zakończeniu praktyk psychiatrycznych.

Wyniki. Przetłumaczona wersja wykazuje wysoką wartość psychometryczną i podobieństwa z wcześniejszymi badaniami. Analiza czynnikowa pozwoliła na wyodrębnienie trzech czynników (wymiar dysfunkcjonalny, funkcjonalny oraz ochronny). Wszystkie czynniki wyjaśniały 52,57\% wariancji, a współczynnik alfa Cronbacha wynosił odpowiednio, $805 ;, 755$ oraz, 828 .

Wnioski. Polska wersja POAS jest wartościowym i rzetelnym narzędziem służącym do badania postrzegania agresji pacjentów przez pielęgniarki.

SŁOWA KLUCZOWE: postrzeganie agresji, student pielęgniarstwa, relacja pacjent - personel.

\section{Wprowadzenie}

Agresja pacjentów wobec personelu medycznego jest problemem, który dotyka pielęgniarki na całym świecie. Statystyki wskazują, że personel medyczny najczęściej ma do czynienia z agresją werbalną [1]. Wyniki metaanaliz wykazały częstsze ataki słowne oraz agresję fizyczną w stosunku do pielęgniarek niż pielęgniarzy. Równocześnie pielęgniarki psychiatryczne stawały się prawie trzy razy częściej ofiarami agresji niż ich koleżanki pracujące na oddziałach somatycznych [2]. Pielęgniarki często postrzegają agresję jako „część swojej pracy”. Jednak jej konsekwencje potrafią być poważne

\begin{abstract}
Introduction. Patient aggression is a serious problem in nursing The research shows a large impact of aggression on the quality of care. It is necessary to study this phenomenon in work of medical staff, however no adequate measurment tools exist in Polish literature.

Aim. This study was to evaluate the psychometric properties of the Polish version of the 12-item Perception of Aggression Scale (POAS).

Material and methods. It consists of translation and back-translation as well as factor analysis. The study involved 150 nursery students after their psychiatry training.

Results. The translated version showed high psychometric properties and excellent similarities with other research. Exploratory factor analysis resulted in three components (dysfunctional, functional and protective dimensions). All factors explained $52,57 \%$ of total variance, and Cronbach's alpha was ,805; ,755 and ,828.

Conclusions. The Polish version of POAS was found to be a valid and reliable tool to examine nurses' attitudes towards patient aggression.
\end{abstract}

KEYWORDS: perception of aggression, nursing student, patient-personnel relationship.

- od złości i poczucia niższości, aż do wypalenia zawodowego i decyzji o odejściu z pielęgniarstwa [3, 4].

Wśród czynników decydujących o zachowaniach agresywnych można wyróżnić wiele elementów. Obecnie to zjawisko postrzega się wieloaspektowo, rozpatrując interakcję wielu czynników, do których tradycyjnie zalicza się cechy pacjenta i odwiedzającego, ich emocje i stan zdrowia [5]. Z drugiej strony literatura wskazuje na cechy samego personelu, wykonywany zawód medyczny, wiek oraz doświadczenie kliniczne. Istotne są także takie czynniki jak postrzeganie agresji oraz postawy wobec niej [6]. 
Badanie postrzegania agresji wśród personelu medycznego wydaje się być istotnym elementem procesu prewencji zachowań agresywnych, gdyż percepcja agresji stanowi jeden z istotnych elementów wyzwalania agresywnego zachowania. Spostrzeganie społeczne, określane także jako poznanie społeczne, jest sposobem, w jaki jednostka myśli o sobie i o innych ludziach. Tym samym warunkuje sposób tworzenia wyobrażeń na temat innych oraz, co za tym idzie - skutkuje określonymi wnioskami na ich temat $[7,8]$. Efektem tego procesu jest postawa oraz określony repertuar reakcji na dany bodziec. Jednostka, dążąc do zastosowania oszczędności poznawczej, często stosuje schematy, których zadaniem jest organizacja wiedzy o świecie. Mają one duży wpływ na myślenie i pamięć. Uruchamiają się często pod wpływem wcześniejszych doświadczeń [9]. Oznacza to, że spostrzeganie agresji będzie warunkować sposób postępowania z pacjentami przejawiającymi takie zachowania. Będzie on względnie stały i uwarunkowany przez szereg czynników. Badania wskazują na większą tolerancję wobec agresji ze strony doświadczonego personelu, co wiązało się z większym poczuciem zadowolenia z pracy zawodowej. Wykazano także, że pozytywne postrzeganie agresji wiąże się z mniejszym poziomem wypalenia zawodowego [10]. Postrzeganie agresji przez personel medyczny warunkuje także stosowane przez niego środki przymusu bezpośredniego [11]. Wykazano zależność pomiędzy postrzeganiem agresji jako zachowania dysfunkcjonalnego a przymusowym podawaniem leków czy stosowanym unieruchomieniem z wykorzystaniem urządzeń technicznych [12, 13]. Podobną zależność dostrzeżono w zakresie stażu pracy i wieku pielęgniarek, a także wcześniejszego bycia ofiarą agresji pacjenta [14]. Badania wskazują także na różnice międzypłciowe. Studentki pielęgniarstwa częściej niż ich koledzy postrzegają agresję jako zachowanie nieakceptowane [15]. Zjawisko to tłumaczyć można powstaniem u studentek silniejszych schematów poznawczych związanych z agresją i ich wpływem na późniejsze zachowanie wobec pacjenta.

Jak wynika z powyższych rozważań, zarówno badanie sposobów, w jaki pielęgniarki postrzegają agresję pacjenta, jak i czynników, które na nią wpływają, jest istotne dla poprawy jakości opieki [16].

Kwestionariusz POAS (ang. Perception of Aggression Scale) powstał, aby lepiej zrozumieć wpływ sposobu postrzegania agresji przez pielęgniarki na opiekę nad pacjentem oraz by móc ocenić konsekwencje agresji w ich pracy zawodowej. Pierwotna wersja narzędzia składała się z 60 pytań. W wyniku analizy czynnikowej udało się wyróżnić trzy podskale - agresja rozumiana jako normalne zachowanie, reakcje związane z przemo- cą oraz zachowanie funkcjonalne [17]. Kolejne badanie, w którym wykorzystano POAS w wersji 32-pytaniowej, pozwoliło na uzyskanie dwóch czynników - agresj jako zachowania dysfunkcjonalnego i niepożądanego oraz funkcjonalnego i zrozumiałego [18]. Kolejne badania niemieckiej wersji językowej potwierdziły istnienie dwóch czynników [19]. Podobne wyniki uzyskano, badając tureckie studentki pielęgniarstwa [20]. W badaniach na grupie szwedzkich pielęgniarek POAS został skrócony do 12 pytań, z których wyróżniono trzy czynniki [21]. Były one identyczne z uzyskanymi w badaniach niemieckich, jednak wskazano na nowy czynnik, który dotyczył postrzegania agresji jako zachowania ochronnego. Okazał się on wrażliwy na szkolenie w zakresie radzenia sobie z agresją [21, 22]. Trzy czynniki uzyskano także w badaniach francuskich oraz chińskich [23, 24].

Analiza uzyskanych w badaniach wyników wskazuje na dużą rozbieżność w postrzeganiu agresji przez pielęgniarki. Z jednej strony jest ona postrzegana jako zachowanie negatywne i nieakceptowane, zasługujące na szczególne potępienie i natychmiastowe działanie. Z drugiej strony pielęgniarki patrzą także na agresję jak na zjawisko wynikające z procesu chorobowego, będące naturalną jego częścią. Należy jednak badać postrzeganie agresji nie tylko w grupie pielęgniarek, lecz także wśród studentów pielęgniarstwa, gdyż pozwoli to na lepszą ocenę ich sposobów rozumienia agresji i - co za tym idzie - lepsze dostosowanie programu nauczania do zmieniającej się rzeczywistości społecznej [20].

W polskiej literaturze brakuje narzędzi służących do badania postrzegania agresji przez personel medyczny. Celem badania było przygotowanie polskiej wersji językowej kwestionariusza POAS (wersja z 12 pytaniami) oraz sprawdzenie jego właściwości psychometrycznych na podstawie postrzegania agresji pacjenta przez studentki psychiatrii.

\section{Materiał i metody}

\section{Grupa badana}

Badaniami objęto grupę 150 studentek pielęgniarstwa, jednak ze względu na błędy w wypełnieniu oraz tendencyjne odpowiedzi w części z kwestionariuszy (wielokrotny wybór tych samych wartości) w ostatecznych analizach uwzględniono 102 osoby (68\%) III roku pielęgniarstwa Wydziału Nauk o Zdrowiu UJ CM w Krakowie. Wiek badanych zawierał się w przedziale 21-27 lat, ze średnią 22,16 (SD 1,047). Studenci pielęgniarstwa zobowiązani są do odbywania praktyk, w czasie których mają możliwość zapoznać się ze specyfiką różnych chorób. Brak doświadczenia klinicznego szczególnie uwrażliwia ich na problemy i trudności zdrowotne osób, z którymi 
się spotykają. W związku z tym, że badania wskazują na narażenie na agresję ze strony pacjentów nie tylko personelu medycznego, ale również studentów, stanowią oni szczególne interesującą grupę badaną.

Kryterium kwalifikacji do badania było zakończenie praktyk na oddziale psychiatrycznym. Było to ważne ze względu na niedawne doświadczenie kontaktu z pacjentem psychiatrycznym, często przejawiającym zachowania agresywne. Badania miały charakter anonimowy, a uczestniczki były informowane o braku negatywnych konsekwencji odmowy. Uzyskano zgodę Komisji Bioetycznej Uniwersytetu Jagiellońskiego Collegium Medicum (nr 122.6120.322.2016).

Narzędziem badawczym był kwestionariusz POAS. W badaniu zastosowano wersję zawierającą 12 pytań. Narzędzie ma formę stwierdzeń zaczynających się od „Agresja to...”. Badany ustosunkowuje się do nich na skali od 1 do 5 - od: zdecydowanie się zgadzam (1) do: zdecydowanie się nie zgadzam (5). Narzędzie zostało przetłumaczone na język polski przez trzech niezależnych tłumaczy, a następnie ponownie przetłumaczone na angielski. Po wyeliminowaniu wszelkich rozbieżności otrzymano spójną wersję polską i angielską, która została wykorzystana w czasie badania.

W celu wyodrębnienia skal kwestionariusza POAS została wykorzystana eksploracyjna analiza czynnikowa. Adekwatność zgromadzonych danych do jej zastosowania sprawdzano za pomocą testu sferyczności Batletta, weryfikującego hipotezę zerową o braku korelacji pomiędzy badanymi zmiennymi, oraz miary KMO (Kaiser-Meyer-Oklin), której akceptowalna wartość wynosi 0,6 [25]. Jako metodę ekstrakcji czynników wybrano metodę osi głównych (ang. principal factor analysis - PFA), bazując na macierzy korelacji. Analizę wykonywano dwukrotnie, dla różnych typów rotacji. W pierwszej kolejności została zastosowana rotacja OBLIMIN (delta = 0). W przypadku korelacji pomiędzy parami czynników nieprzekraczającymi 0,32 stosowano rotację ortogonalną VARIMAX [25]. Zgodnie z najnowszymi zaleceniami [26, 27] wybór ilości czynników oparto na kilku metodach, tj. kryterium Kaisera - liczbę czynników wyznacza ilość wartości własnych powyżej 1, wykresie osypiska, parallel analysis oraz interpretowalności i przejrzystej strukturze uzyskanych czynników. Parallel analysis została przeprowadzona z użyciem makra utworzonego przez O’Connor, które wykorzystuje analizę PCA, permutacje danych surowych oraz 2000 równoległych zbiorów danych [28]. W tej analizie wartości własne, otrzymane na podstawie zgromadzonych danych, porównywane są z losowo wyliczonymi wartościami własnymi. Liczba czynników wyznacza moment, gdy wartości własne obliczone na podstawie surowych danych przekraczają losowe wartości własne.
Minimalny akceptowany ładunek wynosił 0,32, a pytanie było uznawane za złożone, jeżeli jego ładunek przekraczał 0,32 do więcej niż jednego czynnika [25]. Wewnętrzną spójność utworzonych skal badano za pomocą współczynnika alfa Cronbacha; akceptowalny poziom tego współczynnika wynosił minimum 0,7 [29].

Analizy statystyczne zostały przeprowadzone za pomocą SPSS v. 24 (IBM).

\section{Wyniki}

Adekwatność próby mierzona testem Bartletta $(p<, 001)$ oraz miarą KMO (.740) wskazuje na odpowiedni dobór próby do analizy czynnikowej. Uwagę zwraca jednak wysoka korelacja odpowiedzi na pytanie 11 i $12(R=, 707, p<, 001)$, która nie maleje nawet po usunięciu wpływu wszystkich pozostałych pytań kwestionariusza $(R=-, 668)$. Tak wysokie powiązanie między pytaniami znajduje swoje odzwierciedlenie w wynikach analizy czynnikowej.

Kryteria Kaisera oraz parallel analysis wskazały trzy czynniki do wyodrębnienia. Natomiast wykres osypiska wskazał ich aż cztery. Biorąc pod uwagę, że kwestionariusz POAS obejmuje 12 pytań, rozwiązanie czteroczynnikowe wydaje się być nierzetelne, dlatego też zdecydowano się na przedstawienie rozwiązania trzyczynnikowego. Początkowe wartości własne trzech kolejnych czynników, przed wyodrębnieniem, wynoszą odpowiednio $3,87,2,24$ oraz 1,468, przenosząc odpowiednio $32,25 \%, 18,67 \%$ oraz $12,24 \%$ (łącznie $63,15 \%$ ) całkowitej.

Wyniki analizy uzyskane na podstawie rotacji OBLIMIN wykazały niewielkie skorelowanie pomiędzy czynnikami (C1-C2: -0,254; C1-C3: 0,107; C2-C3: -0,303), dlatego też sprawdzono działanie rotacji VARIMAX. Uzyskane wyniki były zgodne, dlatego też w dalszej części przedstawiono wyniki dla rotacji ortogonalnej. W tabeli 1 przedstawiono ładunki czynnikowe poszczególnych pytań, ich zasób zmienności wspólnej po wyodrębnieniu dla każdego pytania, procent zmienności wspólnej po rotacji dla każdego czynnika oraz wartości współczynników alfa Cronbacha.

Uwagę zwraca twierdzenie 6 „Agresja to niepokojące naruszenie w celu zdominowania innych", którego korelacja z pierwszym czynnikiem wynosi jedynie ,378. Tylko ok. 28\% zmienności odpowiedzi respondentów jest przenoszone przez utworzoną strukturę czynnikową. Z drugiej jednak strony twierdzenie to nie wpływa na wewnętrzną spójność tej skali. Usunięcie zdania 6 nieznacznie zwiększa współczynnik alfa Cronbacha $z$,805 do ,808. Kolejne twierdzenie, na które należy zwrócić uwagę, to sformułowanie 10 „Agresja jest formą komunikacji i jako taka nie jest destrukcyjna", które ma wysoki ładunek czynnikowy zarówno w drugim (,596), jak i w trzecim $(, 418)$ czynniku. Usunięcie tego 
zdania z analizy nie zmienia struktury czynnikowej, tj. nadal wynikiem analizy jest rozwiązanie trzyczynnikowe. Współczynnik alfa Cronbacha dla drugiego czynnika po usunięciu stwierdzenia 10 spada z ,755 do ,731.

Tabela 1. Wyniki analizy czynnikowej - rozwiązanie trzyczynnikowe $(\mathrm{N}=102)$

Table 1. Three-factors solutions $(N=102)$

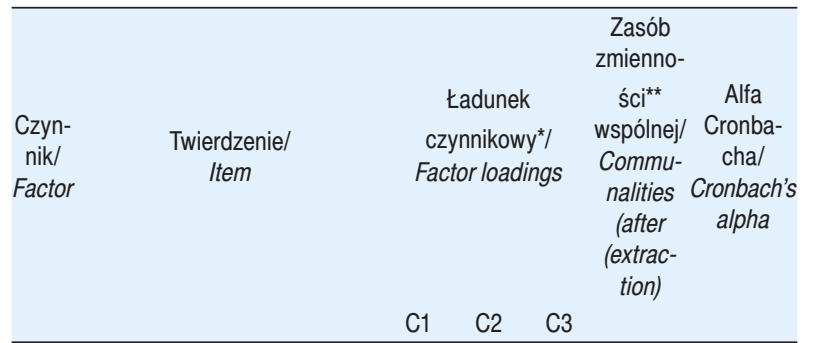

1. Agresja to nieprzyjemne
i odpychające zachowanie/
Aggression is an unpleasant and
repulsive behaviour
2. Agresja jest niepotrzebna
i nieakceptowalna/Aggression is
unnecessary and unacceptable

Wariancja wyjaśniona ${ }^{* \star}$ przez 1. czynnik/ Variance explained by 1th factor (after extraction)

7. Agresja jest początkiem pozytywnych relacji pielęgniarki $\mathrm{z}$ pacjentem/Aggression is the start of a positive nurse-patient relationship

8. Agresja jest zdrową reakcją wyrażania uczucia gniewu/Aggression is a healthy reaction to , 669 $, 743 \quad, 591$ feelings of anger

9. Agresja jest okazją do lepszego zrozumienia sytuacji pacjenta/Aggression is an opportunity to get a better understanding of the patient's situation

, 612 , 408 ,755

10. Agresja jest formą komunikacji i jako taka nie jest destrukcyjna/Aggression is a form of communication and as ,596 , 418 $\quad, 538$ such not destructive

Wariancja wyjaśniona ${ }^{\star \star \star}$ przez 2. czynnik/ Variance explained by 2nd factor (after extraction)
11. Agresja jest sposobem, aby chronić siebie/Aggression is , 877 , 807 a way to protect yourself 12. Agresja jest ochroną swoje3 go terytorium/Aggression is the protection of one's own territory

Wariancja wyjaśniona ${ }^{\star \star *}$ przez 3. czynnik/ Variance explained by 3 nd factor (after extraction) Total variance

C - czynnik/factor, "ładunki poniżej ,32 zostały pominięte/charges below, 32 have been omittted; ** po wyodrębnieniu/after extraction; ${ }^{* * \star}$ po rotacji/after rotation

Źródło: opracowanie własne

Source: author's own analysis

\section{Dyskusja}

Celem badania była adaptacja polskiej wersji kwestionariusza POAS. Po uzyskaniu spójnych wersji językowych, tj. polskiej i angielskiej, przeprowadzono badanie wśród studentek pielęgniarstwa, które zakończyły praktyki na oddziale psychiatrycznym. Eksploracyjna analiza czynnikowa wykazała występowanie trzech czynników, o wysokiej wewnętrznej spójności (współczynniki alfa Cronbacha wynosiły odpowiednio: ,805; ,755 oraz ,828).

Wyniki te są spójne z wcześniejszymi badaniami wykorzystującymi POAS. Zaproponowane w początkowej fazie prac nad kwestionariuszem rozwiązanie dwuczynnikowe, wskazujące na istnienie jedynie dwóch czynników, wydaje się być zbyt ogólne. Uzyskanie trzeciego czynnika pozwala na lepszy wgląd w strukturę spostrzeżeń dotyczących agresji.

Uzyskane czynniki obejmują podobny układ stwierdzeń jak we wcześniejszych badaniach, zatem zasadnym wydaje się utrzymanie wcześniej zaproponowanych określeń czynników, które dotyczą agresji postrzeganej jako zachowanie dysfunkcjonalne i nieakceptowane, zrozumiałe i funkcjonalne oraz ochronne. Wyodrębnienie trzeciego czynnika wskazuje na zbliżone rozumienie istoty agresji pacjenta w różnych kręgach kulturowych oraz braku silnego wpływu doświadczenia zawodowego. Problem ten wymaga jednak dalszej eksploracji badawczej.

Zwracają uwagę wyniki analizy czynnikowej uzyskane w stwierdzeniu 10. Usunięcie tego zdania nie zmienia struktury czynników, powoduje natomiast wzrost znaczenia podskal dotyczących agresji rozumianej jako zachowanie ochronne („Agresja jest formą komunikacji i jako taka nie jest destrukcyjna"). Widoczne jest tu postrzeganie agresji jako zachowania normalnego i otwierającego nowe możliwości w opiece, stąd można wysunąć tezę, że badani mogą mieć trudności z zaakceptowaniem takiego postrzegania agresji. Innym wyjaśnieniem może być sama konstrukcja tego stwierdzenia. W kolejnych wer- 
sjach tej skali można rozważyć jego usunięcie, jakkolwiek nie zrobiono tego w badaniach na innych populacjach.

POAS stanowi wartościowe narzędzie służące do oceny postrzegania agresji pacjentów przez pielęgniarki. Jego stosowanie umożliwi lepsze zrozumienie złożonych mechanizmów kryjących się za przemocą pacjenta wobec personelu, zwiększając tym samym poczucie bezpieczeństwa w pracy. Monitorowanie postrzegania agresji przez personel stanowi również ważny element zmierzający do lepszego zrozumienia jego zachowań wobec pacjenta, pozwala także na uzyskanie wglądu w stosowane środki przymusu bezpośredniego.

Przeprowadzone badanie ma kilka ograniczeń. Przede wszystkim w badaniu wzięły udział studentki tylko z jednego uniwersytetu, co ogranicza generalizację uzyskanych wyników. Konieczne są badania obejmujące bardziej zróżnicowane grupy, mające kontakt $z$ agresją pacjentów. Po drugie należy wziąć pod uwagę tzw. efekt społecznych oczekiwań, który należy rozumieć jako skłonność respondenta do przedstawiania siebie w możliwie jak najlepszym świetle, co może w znaczący sposób wpłynąć na trafność uzyskanych wyników. Należy również pamiętać, że jest to badanie przekrojowe, w którym studentki były badane tylko raz, w ściśle określonym czasie, co uniemożliwia sprawdzenie wpływu upływu czasu lub innych doświadczeń na wyniki POAS. Uzyskane wyniki stanowią ostatecznie wynik eksploracyjnej analizy czynnikowej, opartej na badaniu korelacji pomiędzy poszczególnymi stwierdzeniami, a nie na określonej teorii. Oznacza to, że analizując odpowiedzi innej grupy badanej, możliwe jest uzyskanie innej struktury czynnikowej.

Niemniej jednak postrzeganie agresji stanowi ważny element decydujący o relacji terapeutycznej, dlatego też jest to zagadnienie warte dalszych badań. Mogą one dotyczyć np. tego, jak różne sposoby rozumienia agresji mogą wpływać na bezpieczeństwo pracy personelu pielęgniarskiego. Wskazane są także: poszerzenie badań na inne grupy pracowników ochrony zdrowia i ocena wpływu stażu pracy oraz doświadczenia na postrzeganie agresji. Zagadnieniem wymagającym dalszej eksploracji jest podatność czynnika dotyczącego postrzegania agresji jako zachowania ochronnego na trening zapobiegania agresji.

\section{Wnioski}

Wyniki badań wskazują na przydatność POAS zarówno w badaniach teoretycznych, jak i w praktyce. Wyróżnione podskale pozwalają na lepsze zrozumienie postaw kierujących zachowaniem pielęgniarki w relacji z pacjentem. Wymagającym dalszych badań obszarem jest modyfikacja postaw wobec zachowań agresywnych w stosunku do personelu. Stosowanie POAS umożli- wiłoby mierzenie efektywności działań treningowych zmierzających do zmiany postaw wobec agresji.

Podsumowując, POAS wydaje się być interesującym narzędziem służącym ocenie postaw wobec agresji pacjentów oraz skuteczności szkoleń z tego zakresu, jednak zagadnienie to wymaga dalszej eksploracji badawczej.

\section{Piśmiennictwo}

1. Bilgin H, Tulek Z, Ozcan N. Psychometric properties of the Turkish version of the Perception of Aggression Scale. J Psychiatr Ment Health Nurs. 2011; 18(10): 878-883.

2. Edward KL, Stephenson J, Ousey K, Lui S, Warelow P, Giandinoto JA. A systematic review and metaanalysis of factors that relate to aggression perpetrated against nurses by patients/relatives or staff. J Clin Nurs. 2016; 25(3-4): 289-299.

3. Gascon S, Leiter MP, Andrés E, Santed MA, Pereira JP et al. The role of aggressions suffered by healthcare workers as predictors of burnout. J Clin Nurs. 2013; 22(21-22): 3120-3129.

4. McLaughlin S, Gorley L, Moseley L. The prevalence of verbal aggression against nurses. Br J Nurs. 2009; 18(12): 735.

5. Winstanley S, Whittington R. Aggressive encounters between patients and general hospital staff: staff perceptions of the context and assailants' levels of cognitive processing. Aggress Behav. 2004; 30(6): 534-43.

6. Hahn S, Müller M, Needham I, Dassen T, Kok G, Halfens RJ. Measuring patient and visitor violence in general hospitals: feasibility of the SOVES-G-R, internal consistency and construct validity of the POAS-S and the POIS. J Clin Nurs. 2011; 20(17-18): 2519-2530.

7. Aronson E, Wilson TD, Akert RM. Psychologia społeczna. Poznań: Zysk i S-ka; 2006.

8. Wojciszke B. Psychologia społeczna. Warszawa: Scholar; 2013.

9. Crisp RJ, Turner RN, Kossowska M, Gocłowska M, Gruszka A, Kowalczewska J, Olszewska J. Psychologia społeczna. Warszawa: PWN; 2015.

10. Whittington R. Attitudes toward patient aggression amongst mental health nurses in the 'zero tolerance' era: associations with burnout and length of experience. J Clin Nurs. 2002; 11(6): 819-825.

11. Hui A, Middleton H, Völlm B. Coercive measures in forensic settings: findings from the literature. Int J Forensic Ment Health. 2013; 12(1): 53-67.

12. De Benedictis L, Dumais A, Sieu N, Mailhot MP, Létourneau G, Tran MAM, Lesage AD. Staff perceptions and organizational factors as predictors of seclusion and restraint on psychiatric wards. Psychiatr Serv. 2011; 62(5): 484-491.

13. Keser Özcan N, Bilgin H, Akın M, Boyacıoğlu B, Elçin N. Nurses' attitudes towards professional containment methods used in psychiatric wards and perceptions of aggression in Turkey. J Clin Nurs. 2015; 24(19-20): 2881-2889.

14. Pazvantoğlu O, Gümüş K, Böke Ö, Yıldız i, Şahin AR. Perception of patient aggression among nurses working in a university hospital in Turkey. Int J Nurs Pract. 2011; 17(5): 495-501.

15. Muro C, Tomas C, Moreno L, Rubio V. Perception of aggression, personality disorders and psychiatric morbidity in nursing students. Acta Psychiatr Scand. 2002; 106(s412): 118-120.

16. Nijman I, Palmstierna T, Almvik R, Stolker JJ. Fifteen years of research with the Staff Observation Aggression Scale: a review. Acta Psychiatr Scand. 2005; 111(1): 12-21. 
17. Jansen G, Dassen T, Moorer P. The perception of aggression. Scand J Caring Sci. 1997; 11(1): 51-55.

18. Abderhalden C, Needham I, Friedli TK, Poelmans J, Dassen $\mathrm{T}$. Perception of aggression among psychiatric nurses in Switzerland. Acta Psychiatr Scand. 2002; 106(s412): 110-117.

19. Needham I, Abderhalden C, Dassen T, Haug HJ, Fischer JE. The perception of aggression by nurses: psychometric scale testing and derivation of a short instrument. J Psychiatr Ment Health Nurs. 2004; 11(1): 36-42.

20. Bilgin H, Keser Ozcan N, Tulek Z, Kaya F, Boyacioglu NE, Erol O, Gumus K. Student nurses' perceptions of aggression: An exploratory study of defensive styles, aggression experiences, and demographic factors. Nurs Health Sci. 2016; 18(2): 216-222.

21. Palmstierna T, Barredal E. Evaluation of the Perception of Aggression Scale (POAS) in Swedish nurses. Nord J Psychiatry. 2006; 60(6): 447-451.

22. Arguvanli SC, Karatas N, Baser M. Effect of aggression management training program on knowledge and attitudes of nurses working at psychiatric clinics. Anatolian J Psychiatry. 2015; 16, 5: 323-328.

23. De Benedictis L, Dumais A, Stafford MC, Cote G, Lesage A. Factor analysis of the French version of the shorter 12-item Perception of Aggression Scale (POAS) and of a new modified version of the Overt Aggression Scale (MOAS). J Psychiatr Ment Health Nurs. 2012; 19(10): 875-880.

24. Wong WK, Chien WT. Testing psychometric properties of a Chinese version of perception of aggression scale. Asian J Psychiatry. 2017; 25: 213-217.

25. Tabachnick BG, Fidell LS. Using multivariate statistics. 5th ed. New York: Harper Collins; 2006.
26. Williams B, Brown T, Onsman A. Exploratory factor analysis: A five-step guide for novices. Australas J Paramed 2010; 8(3).

27. Costello AB, Osborne JW. Best Practices in Exploratory Factor Analysis: Four Recommendations for Getting the Most From Your Analysis. Practical Assessment, Research \& Evaluation. 2005; 10(7): 1-9.

28. O'Connor BP. SPSS and SAS programs for determining the number of components using parallel analysis and Velicer's MAP test. Behavior Research Methods, Instruments \& Computers. 2000; 32(3): 396-402.

29. Cronbach LJ. A case study of the split-half reliability coefficient. J Educ Psychol. 1946; 37: 473-480.

Artykuł przyjęty do redakcji: 27.02.2017

Artykuł przyjęty do publikacji: 06.11.2017

Źródło finansowania: Praca nie jest finansowana z żadnego źródła. Konflikt interesów: Autorzy deklarują brak konfliktu interesów.

Dane do korespondencji:

Jakub Lickiewicz

ul. Mikołaja Kopernika 25

31-501 Kraków

tel.: 124247286

e-mail: jlickiewicz@cm-uj.krakow.pl

Zakład Psychologii Zdrowia, Instytut Pielęgniarstwa i Położnictwa Wydział Nauk o Zdrowiu

Uniwersytet Jagielloński - Collegium Medicum 